\title{
Insights into post-editors' profiles and post-editing practices
}

\author{
Olena Blagodarna
}

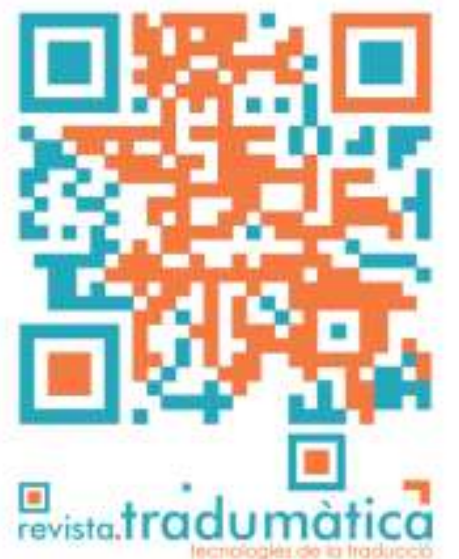

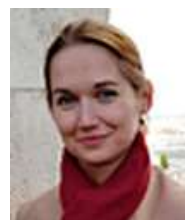

Olena Blagodarna Universitat Autònoma de Barcelona olena.blagodarna@ecampus.uab.cat; ORCID:

$\underline{0000-0001-5234-7119}$
Abstract

The objective of this paper is to share results of the online survey Post-Editing in Action conducted among language experts currently engaged in the MTPE industry. By filling in an online questionnaire the respondents shared information concerning their professional profiles and day-to-day working routines. The survey outcomes give a richer understanding of the common tendencies - e.g. the use of PE mostly for highquality content - and provide information for tailoring translator training programs.

Keywords: machine translation (MT), post-editing (PE), workflow, translator training.

Resum

L'objectiu d'aquest treball és mostrar els resultats de l'enquesta en línia Post-Editing in Action, enfocada en lingüistes experimentats que treballen en la indústria TAPE. Els participants van completar un formulari on van compartir informació dels seus perfils professionals i dels seus fluxos de treball. Els resultats de l'enquesta tenen com a objectiu millorar la comprensió de les tendències més rellevants de la indústria - per exemple, la utilització de postedició principalment per a contingut d'alta qualitat - proporcionant informació per al correcte ajust del marc didàctic per a la formació de traductors.

Paraules clau: $\quad$ traducció automática (TA), postedició (PE), flux de treball, formació de traductors.

Resumen

El objetivo de este trabajo es mostrar los resultados de la encuesta en línea Post-Editing in Action, enfocada en lingüistas experimentados que trabajan en la industria TAPE. Los participantes completaron un formulario dónde compartieron información de sus perfiles profesionales y de sus flujos de trabajo. Los resultados de la encuesta tienen como objetivo mejorar la comprensión de las tendencias más relevantes de la industria - por ejemplo, la utilización de posedición principalmente para contenido de alta calidad proporcionando información para el correcto ajuste del marco didáctico para la formación de traductores.

Palabras clave: posedición, calidad, productividad, formación, direccionalidad, traducción automática. 


\section{Introduction}

In recent decades, all of the factors involved in translation (e.g. ways of processing the texts, formatting, tools, reference materials, etc.) have undergone technological changes and have been affected by it (Martín-Mor et al., 2016). As machine translation (MT) is becoming omnipresent (DePalma et al., 2016; Koponen, 2016; Way, 2018), it has become crucial for industry and academia to keep in line with the increased demand to investigate the whole spectrum of features and characteristics inherent to this emergent phenomenon and to prepare experts for this field.

There has been positive growth in the investigation of the machine translation and post-editing (MTPE). A lot of research has been conducted to study the concerns expressed by the different groups of experts engaged in MTPE (e.g. linguists, LSPs, scholars, and students). The researchers focus on the quality of the output produced by MT engine(s) (Gaspari et al., 2015; Guerberof, 2017) and the throughput that may (or may not) increase as a consequence of the raw MT output (Gaspari et al., 2015; Ruokonen and Koskinen, 2017; Cadwell et al., 2017). The measurement and evaluation of post-editing (PE) effort forms another important line of investigation (Koponen, 2012; Gaspari et al., 2014; Teixeira, 2014; Moorkens et al., 2015), as well as bias and negative predisposition towards MT (Cadwell et al., 2016; Cadwell et al., 2018). This paper is based on the assumption that there is an increasing need to examine and reflect on post-editors' experiences and parameters of PE workflow with a view to MTPE processes facilitation and PE skills enhancement. As such, a collection of first-hand data on post-editors' expertise becomes helpful for those experts and scholars who focus on the development of theories as well as specialized training for the growing needs of the MTPE industry (Kenny and Doherty, 2016; Rossi, 2017).

\section{Aims}

Post-editing involves editing and correcting MT output (ISO 18587, 2017), although language experts engaged in MTPE exercise their duties not only through languagedependent assignments, but they are also expected to be able to understand, manage and run a set of language-independent tasks (Rico Pérez and Torrejón, 2012; Pym, 2013; Austermuehl, 2013). As such, there is a need to zoom into respondents' profiles and experiences and look into the phases of PE workflow to contribute to a clearer picture of the post-editor as one of the primary stakeholders of all MTPE-related processes and help outline the scope of standard practices employed in the field.

The aim of this article is to provide an updated snapshot of post-editors' profiles and working routines. Despite similarity to statistical investigation methods (Wagner, 2010), the key objective of our survey-based research design is to collect real experiences and attitudes in order to provide insights into the salient features of posteditors' expertise from the performer's viewpoint. To that end, this survey addresses individuals working across the broad spectrum of MTPE-related activities. The survey 
outcomes reflect the integration of MTPE into post-editors' day-to-day practices and provide a solid ground for suggestions on the focus of MTPE-related translator training.

\section{Survey setup}

For a participant-oriented study, it is a common practice to use the term 'survey' to describe the study design, while the 'questionnaire' is seen as an instrument (Saldanha and O'Brien, 2014). The theoretical premise behind choosing a questionnaire as our investigation tool is its capacity to obtain quantitative information on a large scale and maintain the anonymity of its participants (Rojo, 2013). The questionnaire Post-Editing in Action was Internet-mediated, which means it could be easily administered through various online channels of communication. A web-based SurveyMonkey platform was used for publishing: this tool allows creation of online surveys and their distribution among multiple participants, collection and summarizing of data in different formats. To prevent the cases of non-response error when the survey participants failed to give answers to all required questions, the tool was configured in such a way that the respondents could submit their answers only if all required fields were filled in. This measure protected us from the predicament of elimination of incomplete questionnaires and helped to maintain the response rate.

On average, online surveys usually obtain lower response rates than other survey models, although this could be compensated for by the potentially higher number of respondents (Vehovar and Manfreda, 2008). The call for participation in the survey was first distributed through databases collected by professional associations and/or federations of translators. To attract more traffic from the translation community a brief project description and the relevant link to the questionnaire were published on a number of social media platforms. The variety of communication channels resulted in the impossibility to gauge exact response rates and to make a claim on the representative coverage. The impossibility of confirming respondents' identity and the fact that it relied on respondents to determine for themselves whether or not they fell into the target group, may be considered as limitations of the present study. Even so, we believe that the answers we collected make an interesting and valid convenience sample for an analysis of profiles and routines of a broad cross-section of translators currently engaged in post-editing. However, our commentaries are tentative, and neither the statistical significance of the findings was assessed, nor broad generalizations were claimed.

It is important to stress that in contrast to other subject fields, translation studies does not manage to engage such a large number of subjects (Saldanha and O'Brien, 2014). According to the MT Industry Report by Grand View Research (2015), the MT market is expected to reach 983 million US dollars by 2022, while the TAUS Machine Translation Market Report (2017) estimates the revenue from the MT market on the level of around 130 million US dollars. Under such circumstances, it is logical to presume that the demand for post-editing services is likely to keep growing. The rapid development of the MTPE translation market is undeniable, yet measuring the share of MTPE projects performed worldwide may seem too ambitious. There are no published 
numbers of the whole population of translators engaged in PE, and so it is not possible to draw conclusions on the representative value of a sample.

This survey is not the first to be carried out in the MTPE field, since a lot of research has already been conducted with professional translators, usually in a commercial context (see Moorkens and O'Brien, 2013; Gaspari et al., 2015; Torres Hostench, Presas \& Cid 2016; Cadwell et al., 2016; Moorkens and O’Brien, 2017). Through this investigation, we wanted to reach out to individuals working across the broad spectrum of MTPE-related tasks. The questionnaire consisted of 15 questions for the sake of the response rate, bearing in mind that "there is no ideal number of questions for a questionnaire” (Saldanha and O'Brien, 2014: 154). The questions were tested during a pilot study with the help of three professional post-editors who volunteered to fill it in. With this measure, it was ensured that there was no ambiguity in the wording of the questionnaire, and that the answers provided sufficient data for further analysis.

The introduction to the questionnaire provided a brief description of the project, information about the anonymity of all participants, and a glossary in order to avoid doubts and ambiguity concerning the terminology used in it. When drafting and administering the questionnaire, CASRO (Council of American Survey Research Organizations) codes and standards for Internet-based surveys were analyzed, where among other highlighted criteria the stress was placed on informed consent. To meet this requirement, all respondents were invited to read the informed consent statement at the beginning of the questionnaire form and give a written agreement to participate in the survey and to provide data for further processing for research purposes only.

The questionnaire included open questions concerned with participants' country of residence, their age, and experience in translation/post-editing; it also featured closed questions to minimize the response time. To measure participants' perception of the issues in question, the response options were arranged in the form of numeric rating scales and frequency scales; the latter comprised four values to reduce the probability of random picking of the mean value and in this way jeopardizing the reliability of survey results. Additionally, a large number of questions contained free text slots aimed at collecting personalized opinions on particular topics. The progress bar at the top showed how many questions remained before the end of the questionnaire. At the end of the questionnaire, the researcher expressed her gratitude to the respondents for taking the time to participate in the survey.

\section{Questionnaire findings}

Section I. To collect the information on respondents' backgrounds, in the first part of the questionnaire we inquired about their countries of residence, age, experience in translation and post-editing and working language pairs. Next, the respondents were asked to present the frequency of professional tasks (translation, post-editing, project management, revision) in their daily routines. They also shared information about the 
perceived average productivity, criteria for establishing rates, distribution of light and full PE jobs and subject fields.

In total, the questionnaire collected responses from 124 survey participants living in 26 countries (Fig. 1):

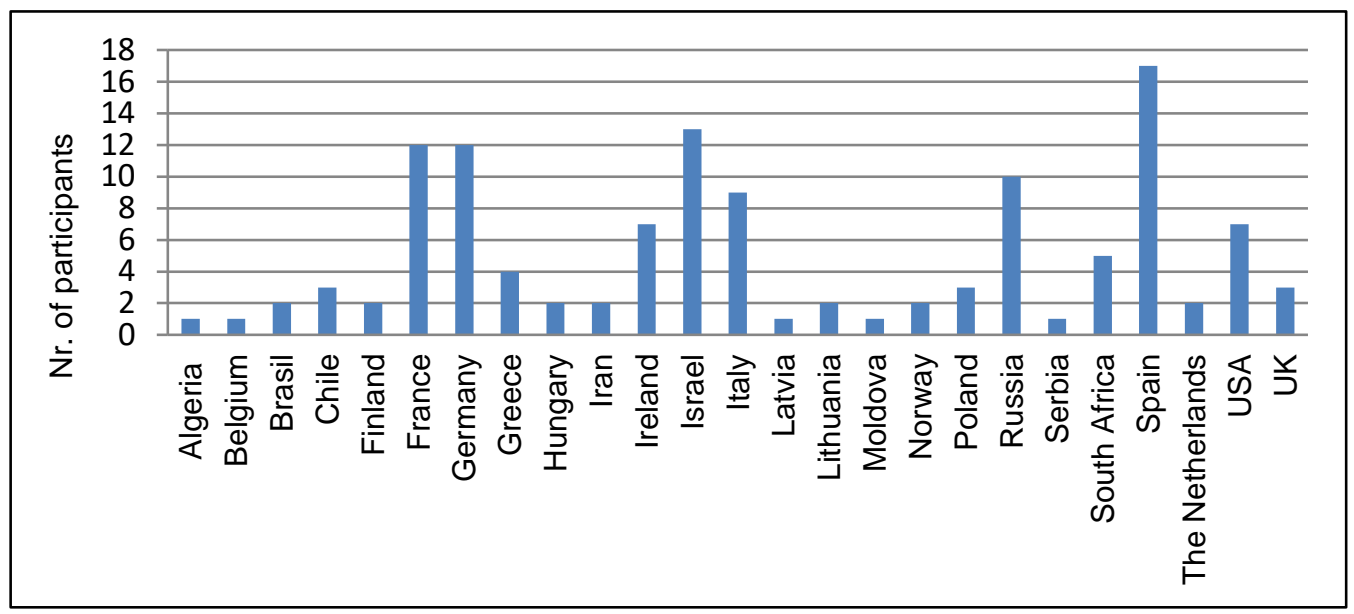

Fig. 1. Respondents' current countries of residence

The age of participants ranged from 22 years old to 77 years old. To represent the data graphically, the breakdown was made into categories with a 10-year margin.

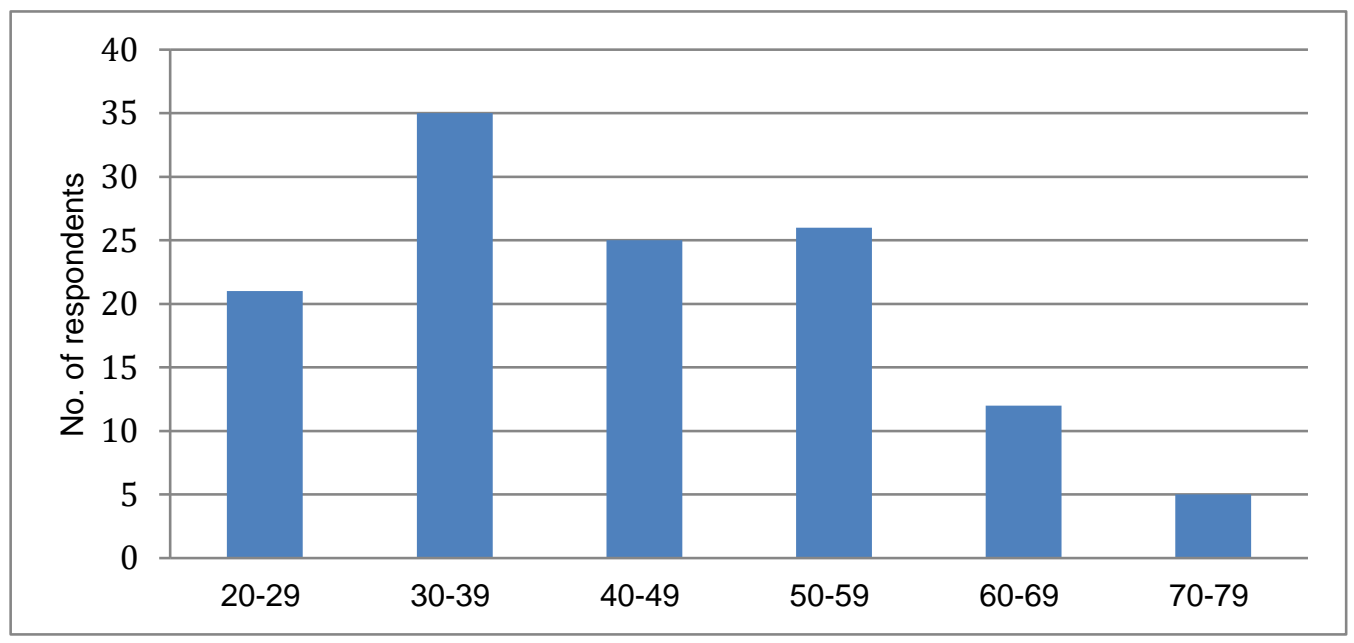

Fig. 2. Respondents' age range

As can be seen in Fig. 2, the participants represent a broad range of ages, where a substantial sub-sample are translators in their early/late thirties, followed by the age groups of those who are 40-49 and 50-59. Hence, the age range of the sample may be described as relatively balanced.

Given the diversity of the survey participants' age, their years of experience in translation and post-editing differed as well. For translation experience 1 and 50 years were indicated as the minimum and the maximum values; post-editing experience made from 1 to 33 years. The participants' data were arranged (Fig. 3) starting with the youngest respondent (aged 22) and finishing with the oldest respondent (aged 77) to examine correlations between the participants' age ( $x$-axis) and years of experience in translation/PE (y-axis): 


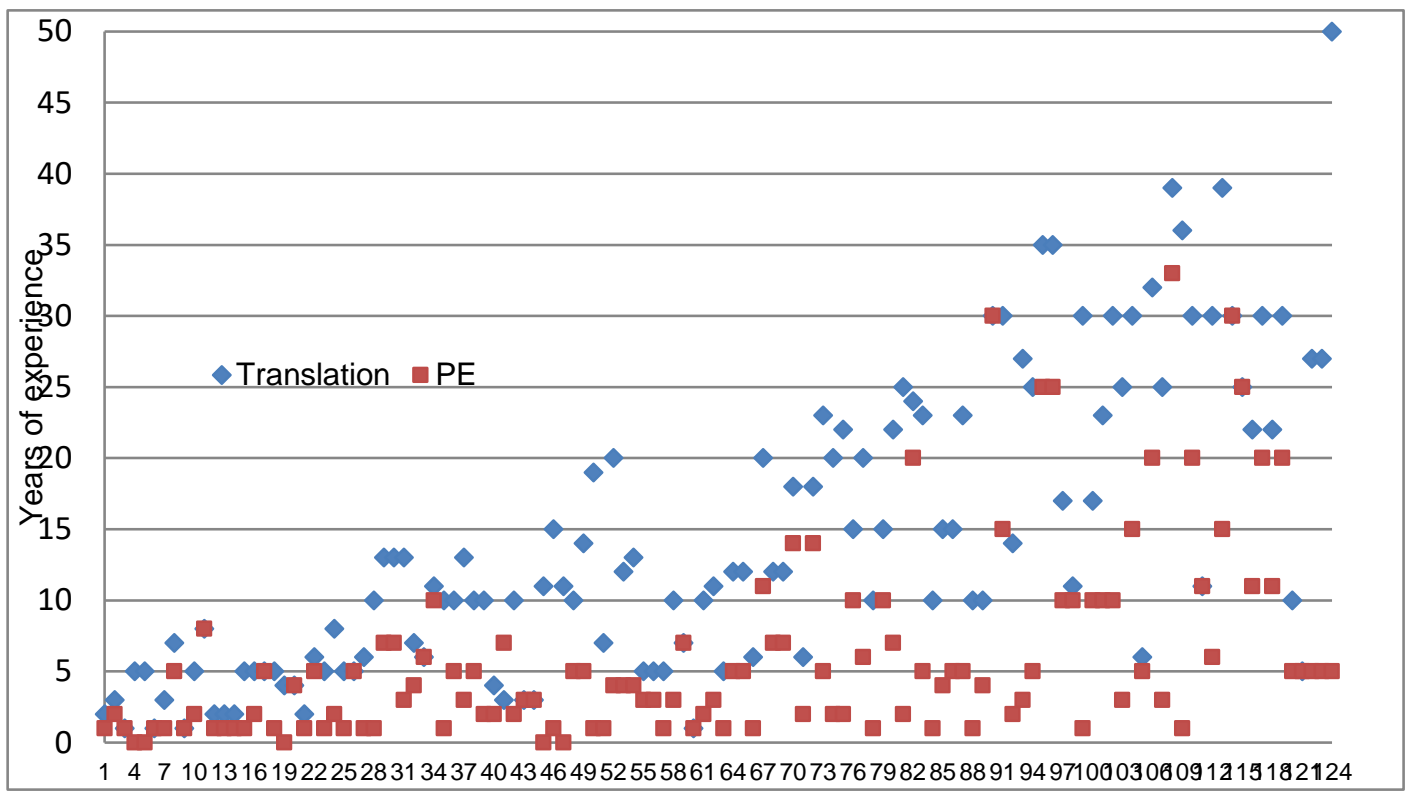

Fig. 3. Years of experience in translation (in blue) and post-editing (in red)

As demonstrated in Fig. 3, experience in translation tends to grow in line with the age of the informants, yet the tendency characterizing PE experience is more heterogeneous. Consequently, it can be assumed that despite availability of MTPErelated modules in the training programs in the recent years (Doherty et al., 2012; Austermuehl, 2013; Kenny and Doherty, 2014; Rossi, 2017), younger participants in the survey did not demonstrate a tendency to be more involved in PE than older participants. Another particular feature of this cross-section is that their experience in $\mathrm{PE}$ was less or on few occasions equaled the number of years dedicated to translation.

Due to the global focus of the questionnaire, no predetermined responses were provided for the question on language pairs required for PE projects. The obtained results reveal that $48 \%$ of respondents usually deal with one source language and one target language; $23 \%$ translate from more than one source language into one target language; $19 \%$ translate from one source language into more than one target language, and $10 \%$ translate from more than one source language to more than one target language. The respondents mentioned Afrikaans, Catalan, Czech, English, French, German, Greek, Hebrew, Italian, Japanese, Norwegian, Russian, Serbian, Slovak, Spanish, Swedish and Yiddish as source languages. The target languages embraced Brazilian Portuguese, Catalan, Chinese, Czech, Danish, Dutch, English, Finnish, French, German, Greek, Hebrew, Hungarian, Italian, Latvian, Lithuanian, Persian, Polish, Portuguese, Russian, Serbian, Slovak, Spanish, Swedish, Ukrainian and Yiddish. This insight confirms the CSA finding (Lommel and DePalma, 2016) on MT gaining traction for high volumes not only in European languages (be they the official languages of the EU or those that play an important role within Europe, e.g. Russian/Ukrainian), but also in the languages outside Europe (e.g. Japanese or Hebrew), given the importance of international trade and cooperation. 
Professional routines of translators and post-editors may include a broad scope of activities, as discussed earlier. To rank the regularity with which each of such tasks is performed, the respondents were asked to rate the perceived frequency of such tasks (Fig. 4):

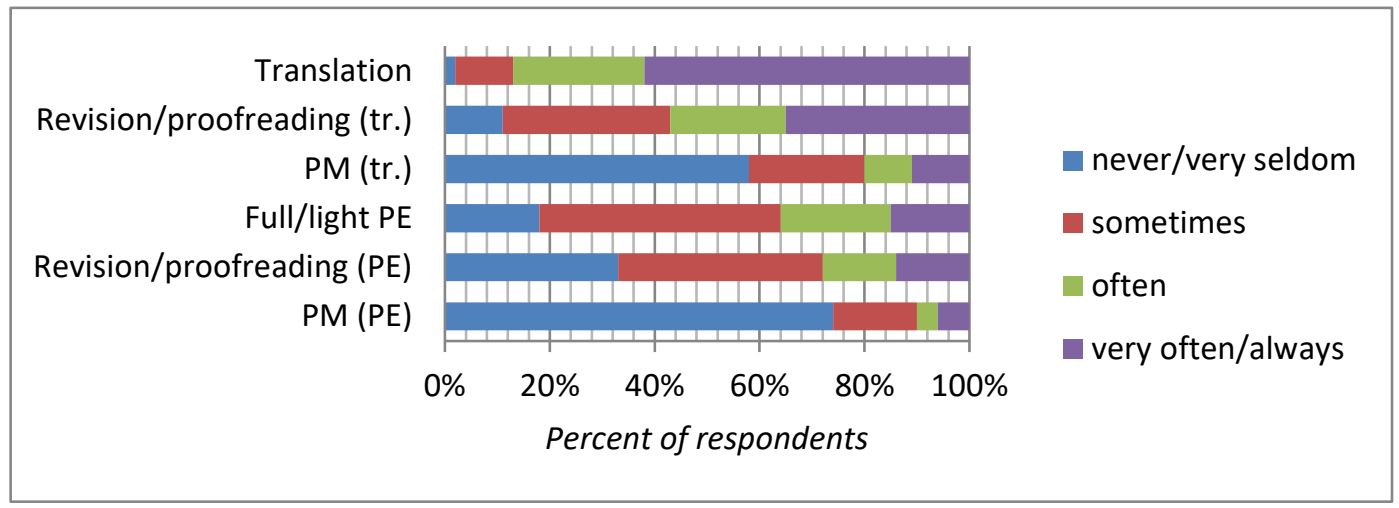

Fig. 4. Frequency of translation/PE-related tasks in the regular workflow

As can be seen, the respondents most commonly do translation and revision/proofreading of translated content. The frequency of performing full/light PE jobs is spread across the available values, with an increase in the "sometimes" segment. Despite a wide variety of professional activities performed by the survey participants, project management of translation/PE projects was reported as the least common type of assignment activity. Similar tendencies could be traced when focusing on the answers of those 15 respondents who reported to having five or more years of experience in PE and to performing this type of assignment (very) often/always (further referred to as "a sub-group of more experienced post-editors").

Scholars and researchers often address the issue of productivity gain provided by the use of the MTPE model (Guerberof Arenas, 2010; Plitt and Masselot, 2010; De Sousa et al., 2011; Robert, 2013; Koponen, 2016), and discuss the broad variety of conditions it involves (García, 2011), including the quality of raw MT output, the subject field(s), source and target languages, experience of post-editors, etc. To make our contribution to the discussion of this parameter, we inquired about average PE productivity in words per hour and/or per day (WPH/WPD) as perceived by the respondents, and got a broad range of results with blurred tendencies (Fig. 5): 


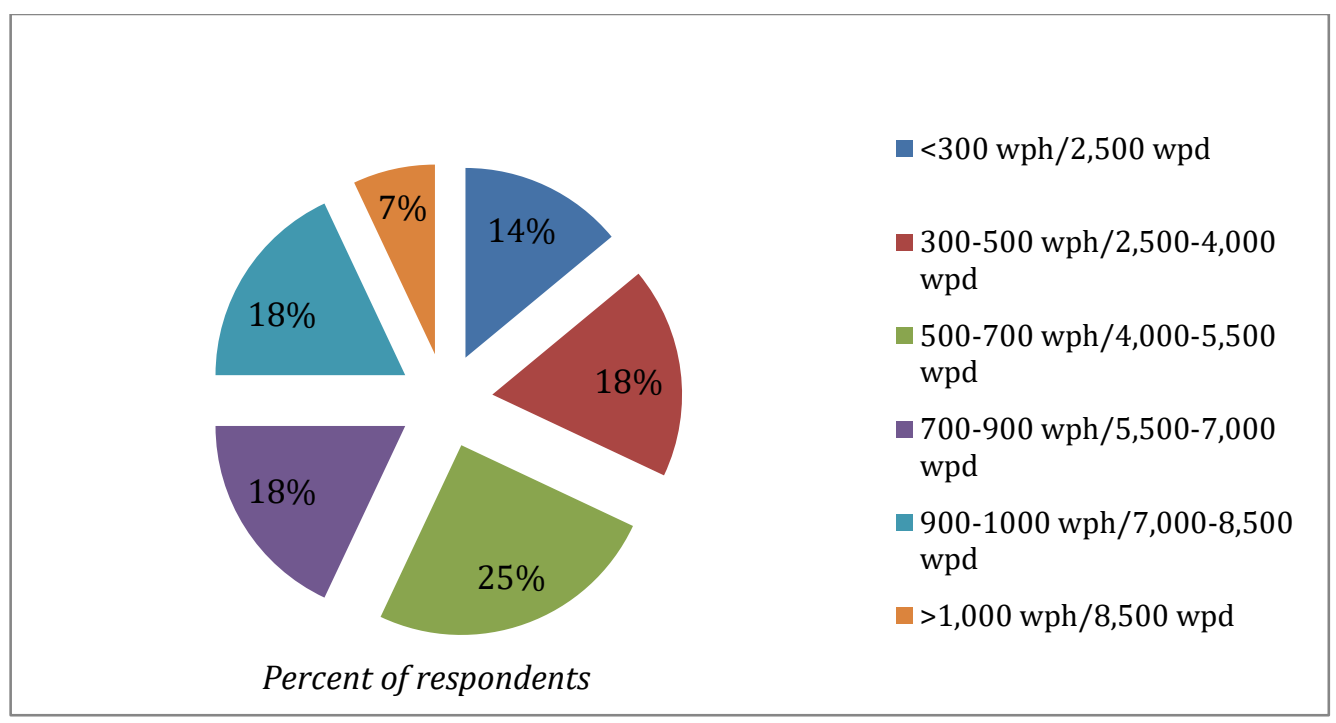

Fig. 5. Respondents' perceived average PE productivity

Quite logically, the top and bottom values of the evaluation scale (i.e. $\geq 1,000 \mathrm{WPH}$ and $\leq 300$ WPH) were chosen by the smallest percent of respondents, while the other values appeared to be more frequent with a slight tendency towards the prevalence of 500-700 WPH productivity rate. However, the answers of the sub-group of more experienced post-editors were skewed towards the segments of 900-1,000 WPH and $\geq 1,000 \mathrm{WPH}$.

It is common knowledge that different factors are involved when of deciding on PE rates: project type, deadline, tools used, etc. However, we were interested in the most common metrics applied by post-editors these days, as reflected in Fig. 7:

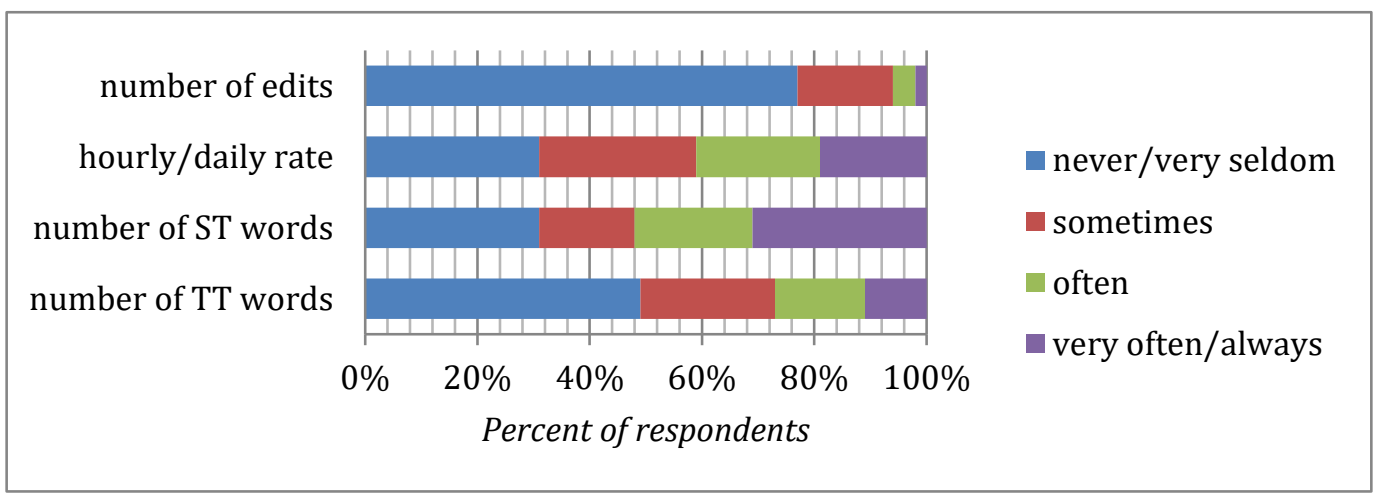

Fig. 7 Metrics used to calculate PE rates

After combining the data from the "very often/always" and "often" categories, the overall tendencies suggested that the number of ST words is the most common criteria for setting PE rates, followed by the category "hourly/daily rate", thus supporting the previous findings in the field (Guerberof Arenas, 2010). On the other hand, the category 'number of edits' is reported as the least frequent, which might be due to the 
fact that the number of changes may not be an accurate measure of the effort involved (Koponen, 2016).

The next question concerned the frequency of light and/or full PE jobs in translators' day-to-day workflow (Fig. 8):

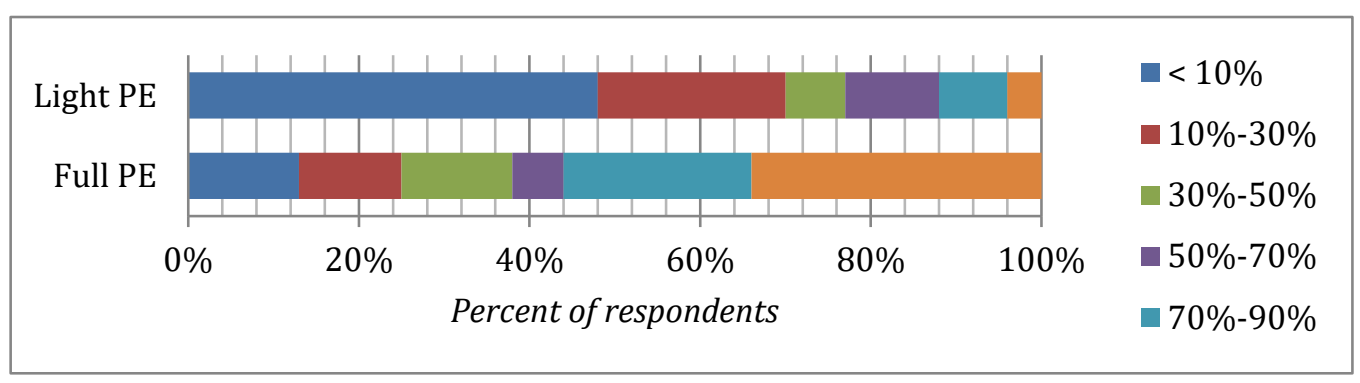

Fig. 8. Full vs. light PE assignments

The tendencies revealed demonstrate that nearly half of the respondents perform light PE in less than $10 \%$ of projects, on the one hand, and full PE in more than $70 \%$ of projects, on the other. Such findings indicate a much higher frequency of PE projects that required "human-like" output quality, the piece of data that should be taken into consideration when drafting training materials for MTPE-related modules.

The last question in this section was aimed at describing the relevance of the most common MTPE industry domains (Gaspari et al., 2015; Torres Hostench, Presas \& Cid, 2016) as perceived by the respondents. The outcomes produce another piece of data that may help adapt PE training to the market requirements (Fig. 9):

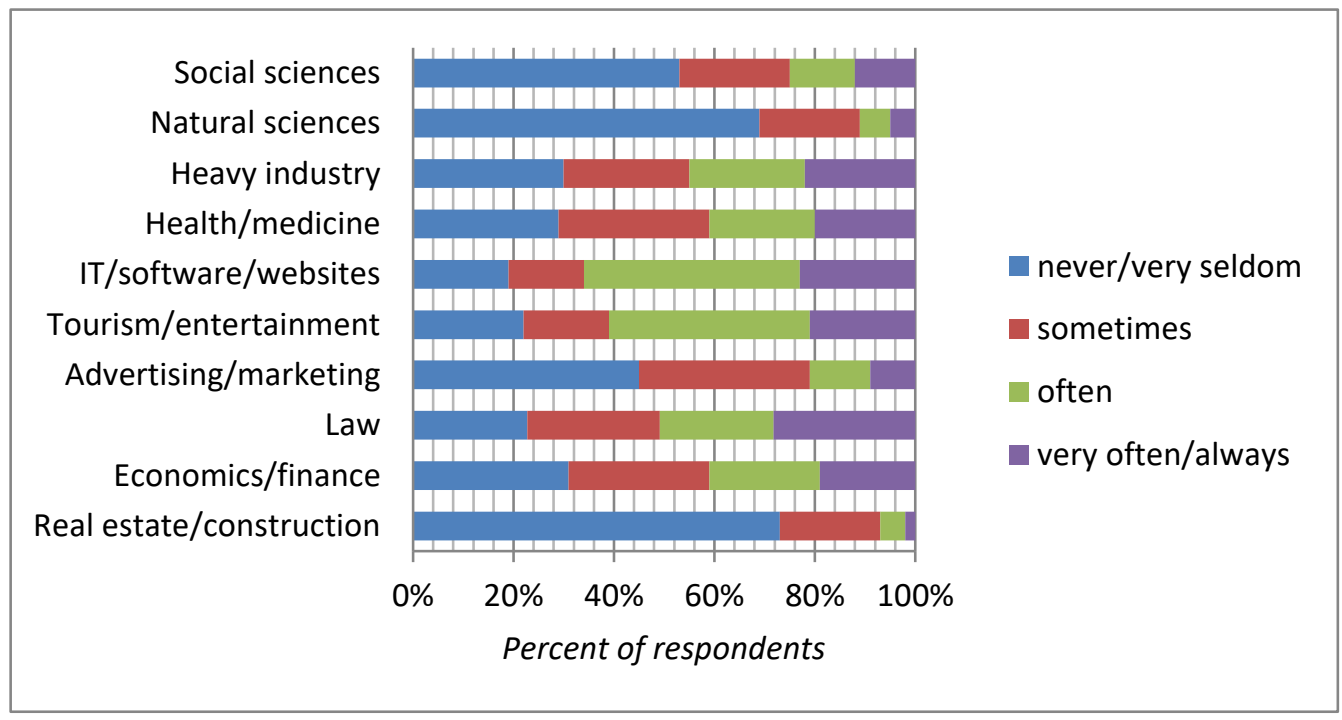

Fig. 9. Regularity of PE task in different subject fields

In line with the observations reported by Machine Translation (MT) Market Analysis by Application and Segment Forecasts to 2022 (2015), the survey participants confirmed prevalence of the domains related to IT, software, website localization, and ecommerce. Among other prospective fields the participants mentioned Law, Tourism 
and Entertainment. The questionnaire results also point to the scarcity of PE projects on Real Estate, Natural and Social Sciences.

Section II. The second part of the questionnaire dealt with PE workflow and opened with a question on PE project preparation routines, e.g. evaluation of raw MT output, terminology extraction or management of terminological databases (Martín-Mor et al., 2016). The starting point of a PE assignment was another important issue - translators may get access to the MT engine, or be given the raw MT output file, or a translation memory with segments of (un)specified origin. The use of software tools and systems is closely related to instrumental competence (Gaspari et al., 2015), so the closing question inquired about whether/how often PE environments, translation memory (TM) systems, generic and complementary quality assurance tools were involved.

First, we focused on the MTPE project preparation phase and the frequency with which certain types of tasks occurred (Fig. 10):

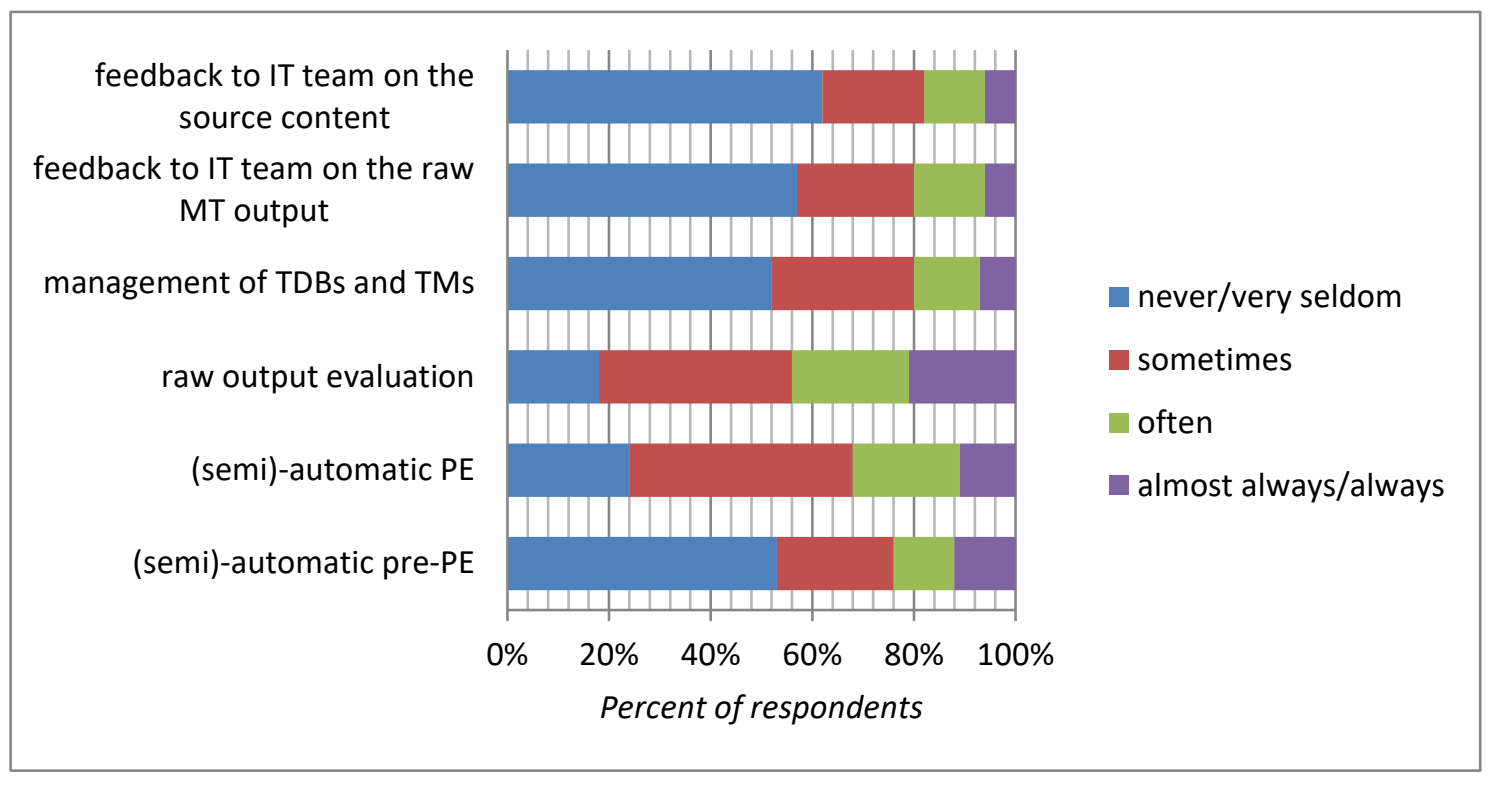

Fig. 10. PE project preparation

The majority of the survey participants indicated that during the project preparation phase the most common task was evaluation of raw MT output quality, which facilitated decision-making on whether it should be post-edited or translated from scratch. Performance of (semi)automatic post-editing operations (e.g. 'search-replace') and management of terminological databases/TMs were also reported as occurring "often" by nearly half of the respondents. On the other hand, the collected responses indicated that the cases of pre-editing of MT input or providing feedback to IT-team(s) on the source and/or output content were scarce.

Similar results were yielded by the sub-group of more experienced post-editors. However, surprisingly enough, the majority ticked the option "never/hardly ever" when describing management of terminological databases/TMs and the use of (semi)automatic pre-editing in their regular workflow. Such outcomes might suggest that 
despite their more extensive PE experience, these translators do not have access to the tools and or skills required to perform these operations, or the scope of their MTPE assignments does not require tasks of this kind. Also, providing feedback to IT teams which is aimed at improvement of all MTPE-related processes and, in particular, PE output quality and throughput, seems to be uncommon among our respondents as well. This apparent contradiction may have different interpretations, one of which is that the majority of post-editors may not have such opportunities and/or the necessary skills; additionally, it could be the case that LSPs consider these practices irrelevant.

In the following question, the participants were asked to share the details of the materials involved in a PE assignment. In particular, we were interested in how frequently source text file(s), raw MT output file(s), previous TM(s) or access to the MT engine appear in their regular workflow (Fig. 11):

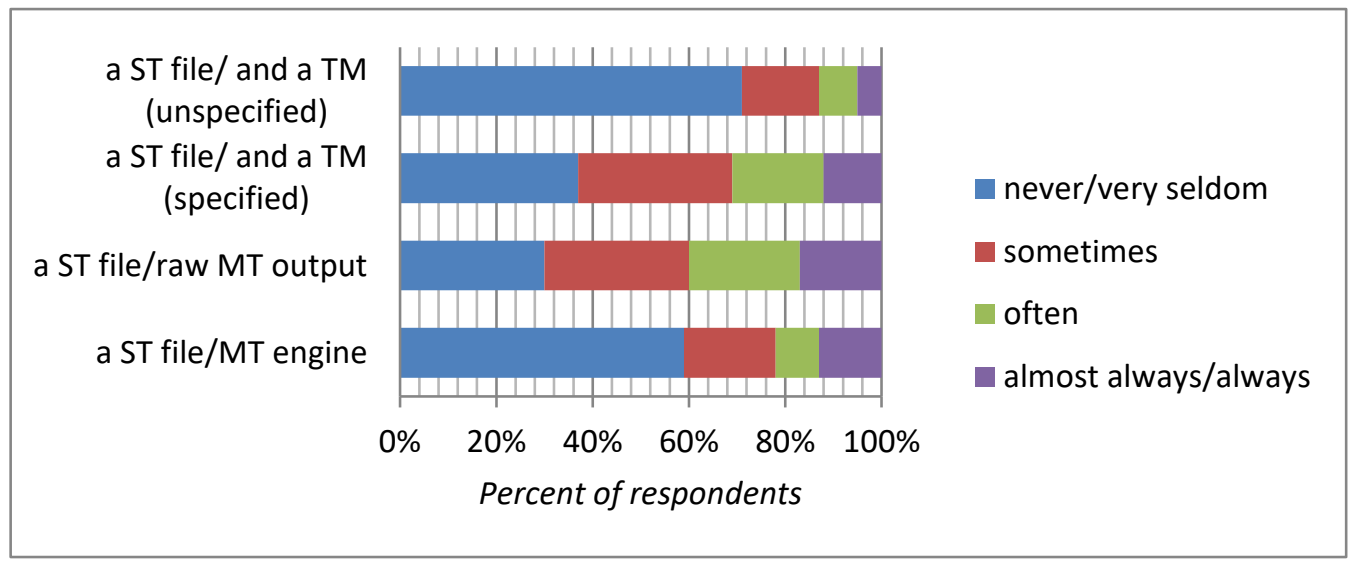

Fig. 11. PE assignment(s)

The available data indicates that the most typical scenario for starting work on a PE assignment includes an ST file and a file with the correspondent raw MT output, or an ST file and a TM with segments of specified origin. Less popular scenarios involve getting an ST file and access to an MT engine and/or a TM fed with segments of unspecified origin. These combinations may be used as a reference point when deciding on the proportion of different types of materials for drafting PE assignments for training purposes.

Finally, the last question in the section zoomed in the instrumental competence of the respondents and inquired about tools and systems used for MTPE needs (Fig. 12): 


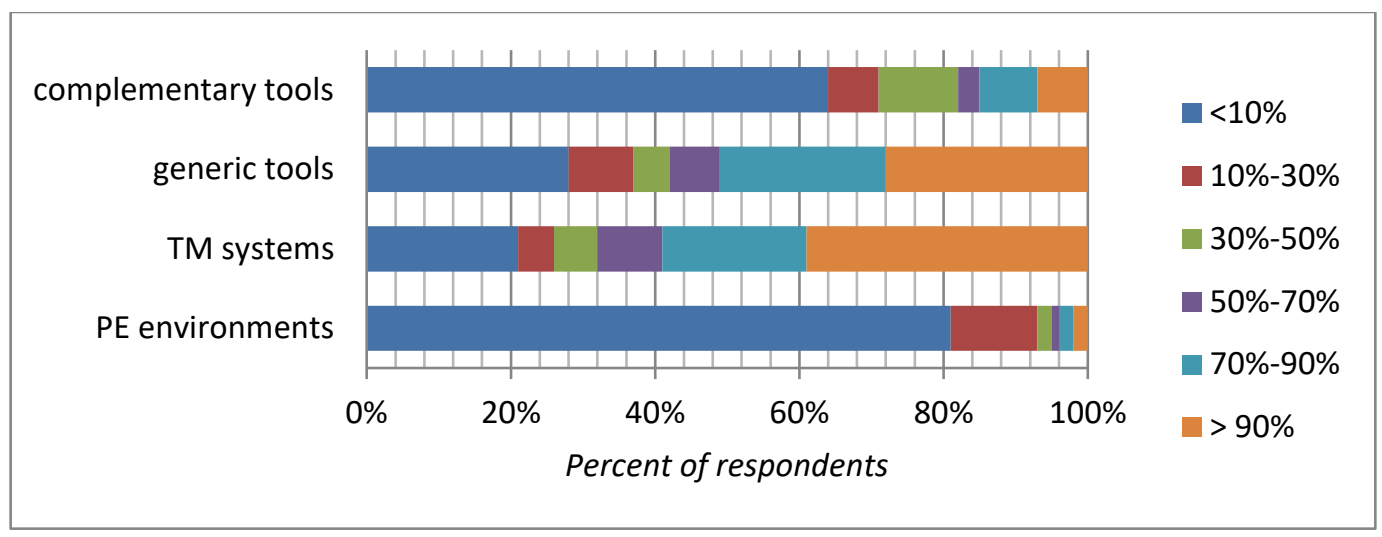

Fig. 12. PE tools and systems

As can be seen, nearly half of the survey participants frequently use TM systems and generic tools (e.g. Word, Excel, etc.). As concerns the use of complementary tools (e.g. QA tools, archive managers, etc.), the sub-group of more experienced post-editors demonstrated more unanimity when describing the share of projects such tools are used for $(\geq 50 \%)$. The survey outcomes also point to very few cases of using PE environments (e.g. PET) in post-editors' workflow, the fact that calls for further investigation of this issue.

\section{Concluding remarks}

The survey conducted provides us with an insight into post-editors' professional profiles and routines. The results shed light on a range of current tendencies in the MTPE field and multiple parameters associated with post-editing as well as help in developing new lines of research.

According to the collected data, the majority of survey participants live in Europe and perform PE across a range of language pairs, among which English was indicated as the most popular source and target language. Their workflow involves PE, translation, revision, and proofreading assignments. None of the participants reported to have more years of experience in PE than in translation. PE throughput rates for the relative majority of the survey participants were defined between $300 \mathrm{WPH}$ and 700 $\mathrm{WPH}$. The survey involved representatives of different age groups, yet according to the collected data the majority of respondents have less than 10 years of experience, which may be attributed to the fact that PE is a relatively new professional occupation. A typical PE scenario is likely to involve full PE of IT-related content, although MTPE projects in Tourism/Entertainment or Law domains are also common - a detail which may be taken into consideration when deciding on the scope of PE-related training content. With regard to the PE workflow, post-editors are likely to start with a source file accompanied with raw MT output or a TM fed with segments of specified origin. Before embarking on such an assignment, evaluation of raw MT output and automation of some PE operations is conducted. As reported by the participants, post-editing involves usage of TM systems and generic tools, while specialized PE instruments are not very common. 
The data collected from more experienced post-editors suggest higher productivity rates (900 WPH - $\geq 1,000 \mathrm{WPH}$ ). The trend towards performing mostly full PE is getting stronger, and nearly half of participants are "never/hardly ever" involved in activities related to project management (e.g. feedback to IT teams on the input/output content or use of complementary tools to extract terminology) or use of PE environments in their workflow.

The survey results yielded authentic information about PE practices adopted among active post-editors, and gave a glimpse of the scope of instrumental and technical skills deployed by them. Its outcomes contribute to raising awareness of the changing role of translators in the light of recent developments in the MTPE sector, complementing the existing findings and may also be used as a reference point for updating and tailoring translator training programs in correspondence with market demands. In addition, the results provide the empirical bases for outlining the scope of competences currently deployed by post-editors, which may help specify translatortraining objectives in such fields as Terminology, Translation Technology, Entrepreneurship or Project Management. Even so, to guarantee an integrated approach to translator training, academia should consider focusing attention on finding the right balance between drafting curricula in conformity with the expectations of the translation industry, on the one hand, and enhancing trainees' MTPE expertise, which would enable translators to go beyond such expectations, on the other

\section{Acknowledgement}

This work was supported by the ProjecTA project Translation projects with Statistical Machine Translation and Postediting, grant number FFI2013-46041-R [MINECO / FEDER, UE; Principal researcher: Dr. Olga Torres Hostench, Grup Tradumàtica, UAB]. Also, we are grateful to both anonymous reviewers for their in-depth comments and suggestions, which have improved this paper.

\section{References}

Austermuehl, F. (2013). "Future (and not-so-future) trends in the teaching of translation technology". Revista Tradumàtica: Tecnologies de la Traducció, n. 11, pp. 326-337. $\langle$ http://revistes.uab.cat/tradumatica/article/view/n11-austermuehl/pdf〉. 〈DOI: https://doi.org/10.5565/rev/tradumatica.46〉. [Last accessed on October 03, 2018].

Cadwell, P.; Castilho, S.; O'Brien, S. \& Mitchell, L. (2016). "Human factors in machine translation and post-editing among institutional translators". Translation Spaces, v. 5, n. 2, pp. 222-243. 〈https://doi.org/10.1075/ts.5.2.04cad〉. [Last accessed on October 03, 2018].

Cadwell, P.; O'Brien, S. \& Teixeira, C. S. (2018). "Resistance and accommodation: factors for the (non-) adoption of machine translation among professional translators". Perspectives: Studies in Translation Theory and Practice, v. 26, n. 3, pp. 
301-321.

〈https://doi.org/10.1080/0907676X.2017.1337210〉. [Last accessed on October 03, 2018].

De Sousa, S. C.; Aziz, W. \& Specia, L. (2011). “Assessing the post-editing effort for automatic and semi-automatic translations of DVD subtitles”. In: Angelova, G. [et al.]. (eds.). International Conference: Recent advances in Natural Language Processing: Proceedings: Hissar, Bulgaria, 12-14 September 2011. pp. 97-103. <http://aclbg.org/proceedings/2011/RANLP\%202011.pdf). [Last accessed on October 03, 2018].

DePalma, D.; Pielmeier, H.; Stewart, R. G. \& Henderson, S. (2016). The language services market: 2016. Common Sense Advisory. 〈http://www.commonsenseadvisory.com/abstractview/tabid/74/articleid/36540/title/t helanguageservicesmarket2016/default.aspx〉. [Last accessed on October 03, 2018].

Doherty, S.; Kenny, D. \& Way, A. (2012). "Taking Statistical Machine Translation to the Student Translator". In: AMTA 2012: The Tenth Biennial Conference of the Association for Machine Translation in the Americas: 28 oct-1 nov. 2012: San Diego, USA. DORAS, DCU Online Research Access Service. 〈http://doras.dcu.ie/17669/>. [Last accessed on October 03, 2018].

Garcia, I. (2011). "Translating by post-editing: is it the way forward?". Machine Translation, v. 25, n. 3, pp. 217. 〈https://doi.org/10.1007/s10590-011-9115-8〉. [Last accessed on October 03, 2018].

Gaspari, F. [et al.]. (2014). "Perception vs reality: Measuring machine translation postediting productivity“. In: O'Brien, S.; Simard, M. \& Specia, L. (eds.). Proceedings of the Third Workshop on Post-editing Techniques and Practices (WPTP-3): The 11th Conference of the Association for Machine Translation in the Americas: October 2226, 2014: Vancouver, BC Canada. [S.L.]: AMTA, pp. 60-72. <https://www.amtaweb.org/AMTA2014Proceedings/AMTA2014Proceedings_PEWorkshop _final.pdf $>$. [Last accessed on October 03, 2018].

Gaspari, F.; Almaghout, H. \& Doherty, S. (2015). "A survey of machine translation competences: Insights for translation technology educators and practitioners". Perspectives: Studies in Translation Theory and Practice, v. 23, n. 3, pp. 333-358. 〈https://doi.org/10.1080/0907676X.2014.979842〉. [Last accessed on October 03, 2018]

Guerberof, A. (2010). "Project management and machine translation". Multilingual computing \& technology, v. 21, n. 3, pp. 34.

Guerberof, A. (2017). "Quality is in the eyes of the reviewer: a reports on post editing quality evaluation”. In: Jakobsen, A. L. \& Mesa-Lao, Bartolomé (eds.). Translation in Transition: Between cognition, computing and technology. Amsterdam; Philadelphia John Benjamins. (Benjamins Translation Library; 133), pp. 188-206.

ISO, International Organization for Standardization. (2017). ISO 18587:2017: Translation services - Post-editing of machine translation output - Requirements. Geneva: ISO. 〈https://www.iso.org/standard/62970.html〉. [Last accessed on May 15, 2018]. 
Kenny, D. \& Doherty, S. (2014). "Statistical machine translation in the translation curriculum: overcoming obstacles and empowering translators". The Interpreter and translator trainer, v. 8, n.2, pp. 276-294. 〈https://doi.org/10.1080/1750399X.2014.936112〉. [Last accessed on May 15, 2018].

Koponen, M. (2012). "Comparing human perceptions of post-editing effort with postediting operations". In: Proceedings of the seventh workshop on statistical machine translation: Montreal, Canada: June 7-8, 2012. Association for Computational Linguistics, p. 181-190. 〈http://www.statmt.org/wmt12/pdf/WMT23.pdf〉. [Last accessed on October 03, 2018].

Koponen, M. (2016). "Is machine translation post-editing worth the effort?: A survey of research into post-editing and effort”. JoSTrans: The Journal of Specialised Translation, n. 25, pp. 131-148. 〈https://www.jostrans.org/issue25/art_koponen.pdf〉. [Last accessed on May 15, 2018].

Lommel, A. R. \& DePalma, D. A. (2016). Europe's leading role in machine translation: How Europe is Driving the Shift to MT. [S.l.]: Common Sense Advisory. 〈http://cracker-project.eu/wp-content/uploads/Europes_Leading_Role_in_MT.pdf〉. [Last accessed on October 03, 2018].

Machine Translation (MT) Market Analysis By Application (Automotive, Military \& Defense, Electronics, IT, Healthcare), By Technology (Rule-Based Machine Translation (RBMT), Statistical Machine Translation (SMT) And Segment Forecasts To 2022. Grand View Research (2015) <https://www.grandviewresearch.com/pressrelease/global-machine-translation-market〉 [Last consulted on April 30, 2018].

Matrín-Mor, A.; Piqué, R. \& Sánchez-Gijón, P. (2016). Tradumàtica. Tecnologies de la traducció. Vic: Eumo. (Biblioteca de traducció i interpretació; 21).

Moorkens, J. \& O'Brien, S. (2013). "User attitudes to the post-editing interface". In: O'Brien, S.; Simard, M. \& Specia, L. Proceedings of the 2nd Workshop on Postediting Technology and Practice (WPTP-2): MT Summit XIV Workshop: Nice, France: September 2, 2013, p. 19-25. 〈http://www.mt-archive.info/10/MTS-2013-W2TOC.htm〉. [Last consulted on April 30, 2018].

Moorkens, J. [et al.]. (2015). "Correlations of perceived post-editing effort with measurements of actual effort". Machine Translation, v. 29, n. 3-4 (December), pp. 267-284. 〈https://doi.org/10.1007/s10590-015-9175-2〉. [Last consulted on April 30, 2018].

Moorkens, J. \& O'Brien, S. (2017). "Assessing user interface needs of post-editors of machine translation”. In: Kenny, D. (ed.). Human issues in translation technology. London: Routledge, p. 127-148.

Plitt, M. \& Masselot, F. (2010). "A Productivity test of statistical machine translation post-editing in a typical localisation context". The Prague bulletin of mathematical linguistics, v. 93, n. 1, pp. 7-16. 〈https://doi.org/10.2478/v10108-010-0010-x〉. [Last consulted on April 30, 2018]. 
Pym, A. (2013). "Translation skill-sets in a machine-translation age". Meta: Journal des traducteurs $=$ Translators' Journal, v. 58, n. 3 (December), pp. 487-503. 〈https://doi.org/10.7202/1025047ar〉. [Last consulted on April 30, 2018].

Rico, C. \& Torrejón, E. (2012). "Skills and Profile of the New Role of the Translator as MT Post-editor". Revista Tradumàtica: technologies de la traducció, n. 10, pp. 166178. 〈DOI: https://doi.org/10.5565/rev/tradumatica.18〉. [Last consulted on April 30, 2018].

Robert, A. M. (2013). "Vous avez dit post-éditrice?: Quelques éléments d'un parcours personnel“. JoSTrans : The Journal of Specialised Translation, n. 19 (July), pp. 2940. 〈https://www.jostrans.org/issue19/art_robert.pdf〉. [Last accessed on October 03, 2018].

Rojo A. (2013). Diseños y métodos de investigación en traducción. Madrid: Síntesis.

Rossi, C. (2017). "Introducing statistical machine translation in translator training: from uses and perceptions to course design, and back again". Revista Tradumàtica: tecnologies de la traducció, n. 15, pp. 48-62.

$\langle$ https://doi.org/10.5565/rev/tradumatica.195〉. [Last accessed on October 03, 2018].

Ruokonen, M. \& Koskinen, K. (2017). "Love letters or hate mail?: Translators' technology acceptance in the light of their emotional narratives". In: Kenny, D. (ed.). Human issues in translation technology. London: Routledge, pp. 26-42.

Saldanha, G. \& O'Brien, S. (2014). Research methodologies in translation studies. London: Routledge.

TAUS. (2017). TAUS Machine Translation Market Report. 〈https://www.taus.net/thinktank/reports/translate-reports/taus-machine-translation-market-report-2017〉.

Teixeira, C. S. (2014). "Perceived vs. measured performance in the post-editing of suggestions from machine translation and translation memories". In: O'Brien, S.; Simard, M. \& Specia, L. (eds.). Proceedings of the Third Workshop on Post-editing Techniques and Practices (WPTP-3): The 11th Conference of the Association for Machine Translation in the Americas: October 22-26, 2014: Vancouver, BC Canada. [S.l.]: AMTA, p. 45-59.

<https://www.amtaweb.org/AMTA2014Proceedings/AMTA2014Proceedings_PEWorkshop _final.pdf). [Last accessed on October 03, 2018].

Torres Hostench, O.; Presas, M. \& Cid-Leal, P. (eds.). (2016). L'ús de traducció automàtica i postedició a les empreses de serveis lingüístics de l'Estat espanyol. 2015. Bellaterra, 2016. 〈https://ddd.uab.cat/record/166753?ln=ca〉. [Last accessed on October 03, 2018].

Vehovar, V. \& Manfreda, K. L. (2008). "Overview: online surveys“. In: Fielding, N.; Lee, R. M. \& Blank, G. The SAGE handbook of online research methods. SAGE. $\langle$ https://doi.org/10.4135/9780857020055.n10〉. [Last accessed on October 03, 2018]. 
Wagner, E. (2010). "Survey research". In: Paltridge, B. \& Phakiti, A. Continuum companion to research methods in applied linguistics, London: Continuum, pp. 2238.

Way, A. (2018). "Quality expectations of machine translation". In: Moorkens, J.; Castilho, S.; Gaspari, F. \& Doherty, S. (eds.). Translation Quality Assessment: From Principles to Practice. Cham: Springer International Publishing. (Machine translation: technologies and applications; 1), pp. 159-178. 〈https://doi.org/10.1007/978-3-319-91241-7_8〉. [Last accessed on October 03, 2018]. 